\title{
Design and Numerical Analysis of Corrugated Helmet Under Impact Test
}

\author{
Kameswara Malapaka, Mohammadreza Yazdifar*, Nick Golsby and Mahshid Yazdi Far \\ School of Mechanical Automotive Aerospace, Coventry University, UK
}

*Corresponding author: Mohammadreza Yazdifar, School of Mechanical Automotive Aerospace, Coventry University, UK

\begin{tabular}{|c|c|}
\hline ARTICLE INFO & ABSTRACT \\
\hline Received: 㗀 May 13, 2021 & \multirow{6}{*}{$\begin{array}{l}\text { In recent years new structures have been developed for sustainability as they are } \\
\text { lighter, with less material usage while sustaining their mechanical properties to be } \\
\text { utilised in the application. One of these structures is a corrugated structure mainly used } \\
\text { in the packaging industry but recently has been recognised by many other applications } \\
\text { as the structure is known for its capabilities against shock absorption. In this study, } \\
\text { BS6655 was used to evaluate corrugated structure in a helmet while an impact occurs to } \\
\text { its front. The dynamic responses of the corrugated helmet were compared with a solid } \\
\text { helmet. The results showed that the corrugated helmet has a higher ability to absorb the } \\
\text { shock and protect the head from injuries in such impact. }\end{array}$} \\
\hline Published: 彗 May 18, 2021 & \\
\hline itation: Kameswara M, Mohammadre & \\
\hline Nick G, Mahshid Yazdi F. Design and Nu- & \\
\hline ical Analysis of Corrug & \\
\hline & \\
\hline
\end{tabular}
35(5)-2021. BJSTR. MS.ID.005766.

Keywords: Corrugated structure; Helmet; Front Impact; Energy Absorption

\section{Introduction}

According to statistics, almost $10-15 \%$ of road accidents lead to severe fatalities [1] and deaths and it is being estimated that there is an increase of 2-3\% every year [2]. However, when motorcycle accidents are compared, the major reasons for motorcycle accidents are low standard and non-standardised helmets, which are made of weak material. Also, when the injured body regions are compared, almost $66.7 \%$ of the accidents cause injury to the head and cause severe fatality, even causing the rider's death [3]. Standardisation is an essential thing in manufacturing any product, similarly, even for helmets, few of the countries have standardised helmet manufacturing, and few of the standards are DOT, ECE 22.05, Snell [4]. These standards are laid after testing the helmet with severe impact tests at different impact points, measuring their performance in each impact test, and continuously improving the helmet strength as they progressed through each impact test.

There are different impact points on the helmet based on ECE 22.05 standards, where the possible high impact forces can appear, and these standards are based on test results in these impact points. These impact points are based on the real-time impact situations caused during an accident. Traditionally materials used in Helmets were polycarbonate, fiberglass and along with the improvements recently, even carbon fibre material is being used for the manufacturing of helmets. Material selection is critically important for the safety of helmet design because whatever design the helmet is made of the material hardness and elastic modulus are critical to minimise the deformation in the helmet when an impact force is impacted on the material [5]. If the material is a weaker material, then the design and layer construction of the helmet does not contribute much to the motorcyclists' safety [6].

Using honeycomb structure in helmet has been analysed by many articles [7-9]. The honeycomb structure is being still considered the most reliable layer structure for the design of helmets [8]. Honeycomb structures reduce the HCI value in both front and rare impact points compare to commercial helmets [9].

Many researchers start to look at effect of material and thickness on helmet shock absorption [10-15]. However, the others are looking at changing the structure to find the effect of shock absorption by different structures by [7,8,16-20]. Fashid looked at the honeycomb structure and found that honeycomb structure would create less injuries from the front to the head of the user [7]. One of the first attempts to define the tolerance of the brain to linear acceleration was the Wayne State Tolerance Curve [21], 
which shows how the brain tolerates higher accelerations if the duration of the pulse is shorter. Based on this curve, the Head Injury Criterion (HIC) was defined:

$$
H I C=\max \left[\left(\frac{\int_{t_{1}}^{t_{2}} a(t) d t}{t_{2}-t_{1}}\right)^{2.5} \cdot\left(t_{2}-t_{1}\right)\right]
$$

Where $\mathrm{a}(\mathrm{t})$ is the measured linear acceleration of the COG in multiples of $g$ and $t_{1}$ and $t_{2}\left(t_{1}<t_{2}\right)$ are any two instants during the impact. Although the HIC is widely used to assess the effectiveness of safety devices, it has been criticised for not considering the real propagation of injury. Corrugated structure stiffness is related to geometrical parameters and core materials that the corrugated is made of. It can be improved by increasing the thickness of corrugated.

$$
\begin{aligned}
& D_{11}=\frac{c}{\lambda} \frac{E h^{3}}{\left(1-v^{2}\right)} \\
& D_{22}=\frac{E h F^{2}}{2}+\frac{E h^{3}}{12\left(1-v^{2}\right)} \\
& D_{66}=\frac{E h^{3}}{24(1+v)}
\end{aligned}
$$

Where $\mathrm{E}$ is the modulus of elasticity of plate material, $\mathrm{v}$ is the Poisson's ratio of plate material $\mathrm{C}$ is the corrugation pitch; $\mathrm{F}$ is the height of corrugation; $\lambda$ is the developed length of unit corrugation, and $\mathrm{h}$ is the thickness of corrugation direction [22].

\section{Methods}

Initially, a solid helmet with a thickness of $10 \mathrm{~mm}$ is created, which can demonstrate the effectiveness of corrugated layer structure. Like the above helmet structure, the solid thickness was replaced with a trapezoidal layer design for the corrugated helmet design. Three layers of corrugated were created. The corrugated cell dimension is represented in Figure 1.3D model of the helmet is imported from Solid works to Abaqus to predict shock absorption and monitor the performance of both helmets under dynamic impact. The assembled configuration of the helmet in ABAQUS is shown in Figure 2. The material defined based on Table 1 the material for the helmet was assigned as High Carbon Fibre with the following material properties. Surface to surface contact algorithm is defined between helmet and rigid body. The mesh model three-dimensional tetrahedral ('tet') elements of type C3D10H are applied. Impact of a body toward helmet are performed, and velocity is applied based on BS6658. The frontal impact conditions are considered for both solid and corrugated helmets.

Table 1: Material properties of the helmets.

\begin{tabular}{|c|c|c|c|}
\hline Material properties & $\boldsymbol{\rho}\left(\mathbf{k g} / \mathbf{m}^{\mathbf{3}} \mathbf{)}\right.$ & $\mathbf{E}(\mathbf{G P a})$ & $\mathbf{V}$ \\
\hline High Carbon Fibre & 1800 & 135 & 0.283 \\
\hline
\end{tabular}
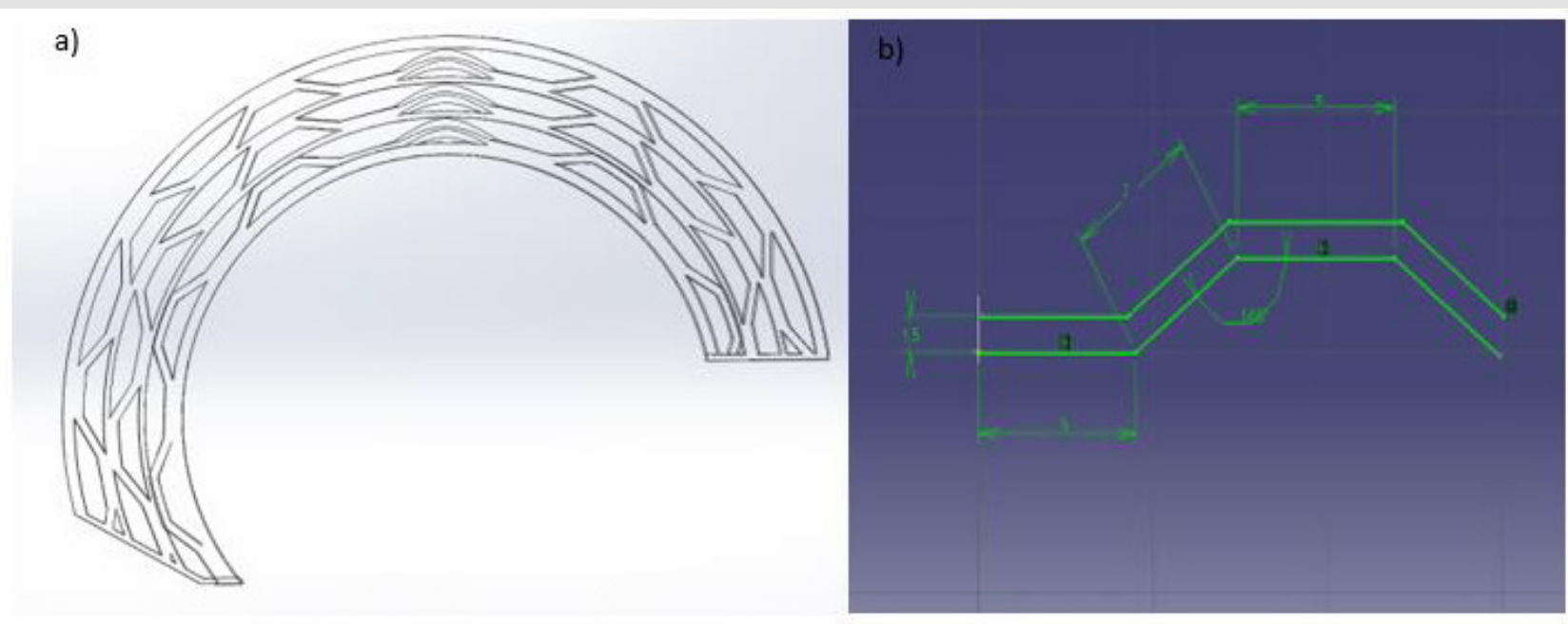

Figure 1: Corrugated helmet.

a) Wireframe

b) Geometrical dimension of corrugated ( $\mathrm{mm})$. 


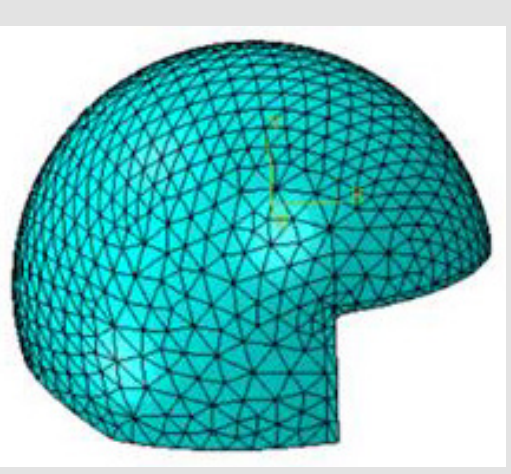

Figure 2: Tetrahedral element mesh for helmets.

\section{Results and Discussion}

The front impact shows the displacement in the corrugated helmet, and this displacement shows how much shock the structure can absorb.

\section{Deformation}

The deformation of both structures is shown in Figure 3. Corrugated structure deformed more than solid structure, especially at the point of contact. However, the stiffness of the corrugated structure is not as high as the solid structure.

\section{Kinetic Energy}

Kinetic energy is higher in corrugated structures compare to the solid structure. This kinetic energy represents absorbed energy by design. Corrugated structures absorbed more energy if impact happens and can prevent higher safety for the user. The constant decrease in kinetic energy represents that the shock absorption of both designs has been ultimately achieved (Figure 4).
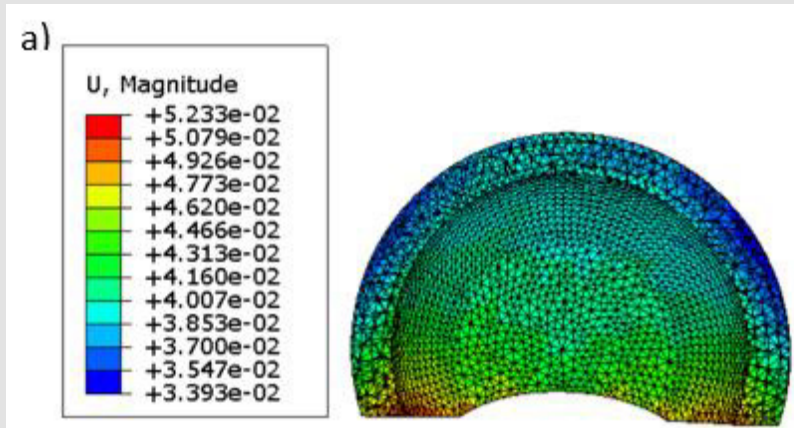

b)

Figure 3: Displacement of the helmets under dynamic impact.

a) solid structure

b) corrugated structure.

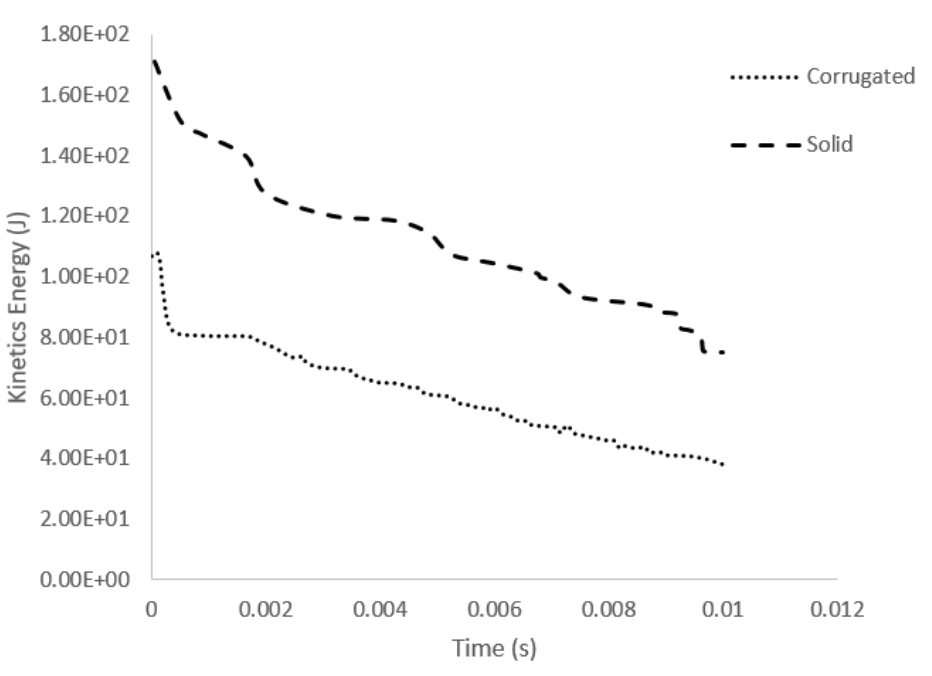

Figure 4: Kinematics energy of both corrugated and solid helmets under front impact test in terms of time. 


\section{Acceleration}

Acceleration in terms of time represents the ability of each helmet to prevent head injury. HCI can be estimated as one of the factors to compare the helmet structure. The lower the HCI is, the less significant head injury will happen. Both structures show that the acceleration is way below $2940 \mathrm{~m} / \mathrm{s}^{2}$ based on JIS T813. There is a change in the slop of the acceleration for corrugated structure before the high peak, which indicates the deflection in the shell based on Gilchrist and Mill's findings [10]. However, there is a change in the slop in the solid structure after the peak acceleration, which shows the deflection starts after peak acceleration. Both designs indicated that the helmet achieved complete energy absorption. After the peak acceleration, both structures show a reduction in acceleration which suggests the decrease in HCI. The reduction of HCI illustrates a reduction of damage to the head of the user. It is clearly stated that at the first peak, the most shock absorption occurs when the deflection happens in a corrugated structure and does not let the force transfer to the head (Figure 5).

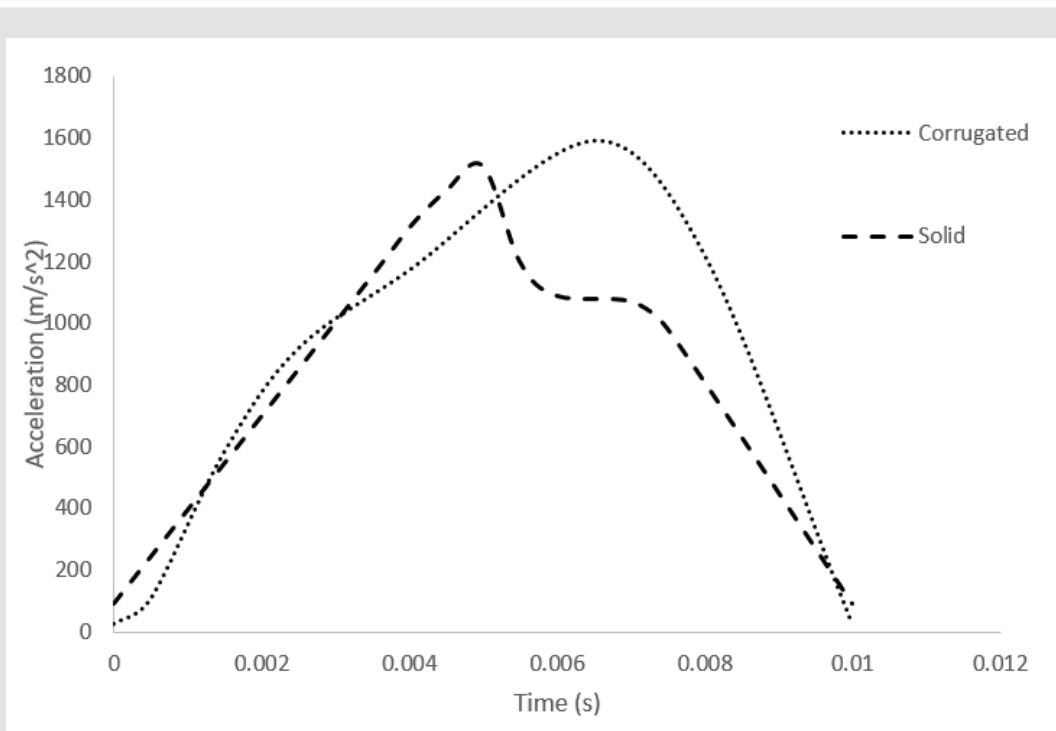

Figure 5: Acceleration of both corrugated and solid helmets under front impact test in terms of time.

\section{Conclusion}

In this research, the comparison of corrugated structure with solid was considered in a helmet application. Both structures are safe to be used and provide sufficient HCI. However, the corrugated structure shows higher impact absorber performance while the front impact happens to transfer less energy to the head. The cushioning and shock absorption of corrugated structure improve the helmet's safety while having a lighter helmet.

\section{References}

1. G Ryan (1992) Improving head protection for cyclists, motorcyclists, and car occupants, World Journal of Surgery 16(3): 398-402.

2. B Zeng, A Picincu, B Zeng (2021) What Are the Leading Causes of Motorcycle Accidents? PONBEE.

3. (2021) Sharp.dft.gov.uk.

4. (2021) BSI-BS 6658-Specification for Protective helmets for vehicle users. Engineering 360, Standards.globalspec.com.

5. G Lu, T Yu (2003) Energy absorption of structures and materials. Boca Raton: CRC Press.

6. L Gibson, M Ashby (2010) Cellular solids. Cambridge: Cambridge Univ. Press.
7. F Kholoosi, S Galehdari (2017) Design and Analysis of a Helmet Equipped with Graded Honeycomb Structure Under Impact of Flat and Hemi-spherical Anvils, Procedia Engineering 173: 1299-1306.

8. A Eyvazian (2016) Mathematical Model for Thin-walled Corrugated Tube under Axial Compression, MATEC Web of Conferences 40: 2010.

9. G Caserta, L Iannucci, U Galvanetto (2011) Shock absorption performance of a motorbike helmet with honeycomb reinforced liner, Composite Structures 93(11): 2748-2759.

10. N Mills, A Gilchrist (1991) The effectiveness of foams in bicycle and motorcycle helmets, Accident Analysis \& Prevention 23(2-3): 153-163.

11. L Di Landro, G Sala, D Olivieri (2002) Deformation mechanisms and energy absorption of polystyrene foams for protective helmets, Polymer Testing 21(2): 217-228.

12. M Tovey (1988) Creative design: a new look at design principles, Design Studies 9(3): 191.

13. F Shuaeib, A Hamouda, S Wong, R Umar, M Ahmed (2007) A new motorcycle helmet liner material: The finite element simulation and design of experiment optimization, Materials \& Design 28(1): 182-195.

14. N Mills, S Wilkes, S Derler, A Flisch (2009) FEA of oblique impact tests on a motorcycle helmet, International Journal of Impact Engineering 36(7): 913-925.

15. P Pinnoji, P Mahajan, N Bourdet, C Deck, R Willinger (2010) Impact dynamics of metal foam shells for motorcycle helmets: Experiments \& numerical modeling, International Journal of Impact Engineering 37(3): 274-284. 
16. D Zenkert, A Shipsha, P Bull, B Hayman (2005) Damage tolerance assessment of composite sandwich panels with localised damage, Composites Science and Technology 65(15-16): 2597-2611.

17.S Galehdari, M Kadkhodayan, S Hadidi-Moud (2015) Analytical, experimental and numerical study of a graded honeycomb structure under in-plane impact load with low velocity, International Journal of Crashworthiness 20(4): 387-400.

18. S Galehdari, H Khodarahmi (2016) Design and analysis of a graded honeycomb shock absorber for a helicopter seat during a crash condition, International Journal of Crashworthiness 21(3): 231-241.

19. G Petrone, S Rao, S De Rosa, B Mace, F Franco, et al. (2013) Behaviour of fibre-reinforced honeycomb core under low velocity impact loading, Composite Structures 100: 356-362.

ISSN: 2574-1241

DOI: 10.26717/BJSTR.2021.35.005766

Mohammadreza Yazdifar. Biomed J Sci \& Tech Res

(c) (P) This work is licensed under Creative BY Commons Attribution 4.0 License

Submission Link: https://biomedres.us/submit-manuscript.php
20. V Caccese, J Ferguson, M Edgecomb (2013) Optimal design of honeycomb material used to mitigate head impact, Composite Structures 100: 404412.

21. A. King (2000) Fundamentals of Impact Biomechanics: Part I Biomechanics of the Head, Neck, and Thorax, Annual Review of Biomedical Engineering 2(1): 55-81.

22.N Alshabatat (2016) Design of Corrugated Plates for Optimal Fundamental Frequency, Advances in Acoustics and Vibration 2016: 1-9.

$\begin{array}{ll}\text { BIOMEDICAL } & \text { Assets of Publishing with us } \\ \text { RESEARCHES } & \text { - Global archiving of articles } \\ & \text { - Immediate, unrestricted online access } \\ & \text { - Rigorous Peer Review Process } \\ & \text { - Authors Retain Copyrights } \\ \end{array}$

